Check for updates

Cite this: RSC Adv., 2017, 7, 21721

\title{
Highly efficient large-scale preparation and electromagnetic property control of silica-NiFeP double shell composite hollow particles $\uparrow$
}

\begin{abstract}
Bin Liao, (D) ab Zhenguo An (D) *a and Jingjie Zhang (D) *a
Double shell composite hollow particles (DSCHPs) with silica (inner shell) and magnetic metal (outer shell) shells are prepared on a large scale through a novel cost effective strategy involving spray drying, simultaneous silicification and surface decoration with active sites, and finally directed growth of magnetic metal shells. The silica shell formed through silicification of silicate possesses good chemical durability and thermostability. The spherical shape and hollow structure are well reserved during the silicification in an acid environment and calcination at a high temperature of $1300{ }^{\circ} \mathrm{C}$. The DSCHPs with $\mathrm{Ni}-\mathrm{Fe}-\mathrm{P}$ alloy shell exhibit a maximum reflection loss (RL) of $45.92 \mathrm{~dB}$ at $15.92 \mathrm{GHz}$ and a broad effective absorption bandwidth (the frequency range in which the RL value exceeds $10 \mathrm{~dB}$ ) of $4 \mathrm{GHz}$ with a thin absorber layer thickness of $1.5 \mathrm{~mm}$. Moreover, the hollow structure endows the DSCHPs with low real density (1.1-2.35 $\mathrm{g} \mathrm{cm}^{-3}$ ) and makes them promising candidates as low-density magnetic materials and microwave absorbents. The new strategy reported here has the potential to be extended to the controlled preparation of various double or multishell composite hollow particles with a robust silica shell as support and various metal, alloy or metal oxides as functional shells.
\end{abstract}

Received 6th March 2017
Accepted 13th April 2017

DOI: 10.1039/c7ra02710a

rsc.li/rsc-advances

controlled synthesis of high performance microwave absor-

\section{Introduction}

With the increasing usage of electrical and electronic devices, such as mobile phones, TVs, digital computers, and radar systems, electromagnetic wave radiation has become a serious threat to the health of human beings, the success of weapons in the battlefield, and the normal operation of precise electronic devices. ${ }^{\mathbf{1 - 4}}$ To overcome this problem, more and more effort has been devoted to develop excellent microwave absorption materials with strong absorption in a broad bandwidth, among which those with thinner absorbing layers and lightweight properties have attracted special attention..$^{5-9}$ To obtain low density absorbents, investigations have been carried out aiming at decreasing the density of the absorbing layer through rational design and

${ }^{a}$ Technical Institute of Physics and Chemistry, Chinese Academy of Sciences, Beijing 100190, China. E-mail: zgan@mail.ipc.ac.cn; jjzhang@mail.ipc.ac.cn; Fax: +86 10 82543690; Tel: +861082543690

${ }^{b}$ University of Chinese Academy of Sciences, Beijing 10049, P. R. China

$\dagger$ Electronic supplementary information (ESI) available: Detailed chemical agent concentrations and reaction conditions for different DSCHPs. XRD patterns of different DSCHPs, EDX spectra of the SSHPs after silane coupling and sensitization, particle size distribution of different SSHPs, XPS spectra, TG-DTA curves of the SSHPs and the ASHPs, optical microscopy, SEM and EDX element mapping images of different DSCHPs, the electromagnetic parameters and absorption properties of similar samples, the schematic diagram of electromagnetic microwave absorption mechanism for the DSCHPs, cole-cole semicircles for different DSCHPs. See DOI: 10.1039/c7ra02710a bents with hollow spherical morphology. ${ }^{10}$ The hollow interior leads to decreased density of the absorbents and well sphericity providing better filling coefficient when mixed with matrix. On the other hand, it is found by extensive studies that the hollow structures, except for the lightweight, could also bring extra interfacial polarization and reflection and scattering in hollow space, which contribute remarkably to the microwave absorption properties. ${ }^{11-13}$ In the past few years, a variety of strategies have been employed for the manufacture of hollow microwave absorbents. ${ }^{\mathbf{1 4 , 1 5}}$ For instance, Panigrahi et al. reported the synthesis of hollow polypyrrole (HPPy) spheres and its silver nanocomposites (HPPy/Ag), and it was found that such novel morphology acts as a conducting trap in the dissipation of electromagnetic wave by internal reflection on the shells of the hollow spherical structure. However, to meet the ever increasing application demand on large sale and cost effective preparation, high structure stability and fine property control, hollow structured absorbents, especially those with multicomponent shells, need to be explored in more detail.

For the formation of hollow structures, two kinds of synthetic strategies are generally employed: the template assisted strategies (e.g. silica, carbon, organic microsphere, assistant surfactant templates) and the template-free ones (Ostwald ripening and the Kirkendall effect, etc.). ${ }^{16-19}$ For example, Genqiang Zhang and coworkers synthesized multishelled mixed metal oxide hollow by a new "penetration- 
solidification-annealing” strategy through carbonaceous spheres, and the complex hollow spheres exhibit largely enhanced lithium storage properties. ${ }^{20}$ Jie Chen and coworkers developed a new strategy combining sol-gel preparation and hydrothermal treatment to construct a series of well-defined sandwich metal oxide-noble NPsmetal oxide hollow spheres, simultaneously the $\mathrm{SiO}_{2}$ templates etched away by superhot water. ${ }^{21}$ However, most of the approaches are usually tedious and costly, involving sacrificial templates, complicated multi-stages, timeconsuming reaction processes, and the excess use of organic solvents. More importantly, the elimination of templates may inevitably leads to composition and structure variation of the shells. Meanwhile, the elimination of templates may also result in less robust shells and make the hollow structures easy to collapse, which can bring tremendous performance decline in practical applications. On the other hand, traditional template-free strategies for the preparation of hollow structure always suffer from tedious reaction process, high dependence on the inherent nature of materials and low efficient. Therefore, for both practical application and academic study, it is of great importance to develop simple, controllable, cost effective and industrial acceptable strategies to achieve large scale fabrication and fine property control of hollow structures with high stability.

Herein, we report a straightforward, green and versatile synthesis of double shell composite hollow particles with silica (inner shell) and magnetic metal (outer shell) shells in large scale. Firstly, hollow particles with uniform amorphous shells were obtained by spray drying using low cost water glass as starting material. By properly monitoring the reaction parameters, ${ }^{22,23}$ hollow particles with gradient in diameter distribution were prepared. Secondly, the hollow particles underwent a stepwise surface activation (couplingsensitizing-activating) process to decorate active sites for the directed assembly of the magnetic metal shell. ${ }^{24}$ Interestingly, with rationally designed reaction condition, the silicification of the water glass shell can be achieved simultaneously during the above mentioned surface activation process, and hollow particles with surface activated silica-shells were obtained. Finally, magnetic metal shells were formed through in situ chemical reduction and assembly in a rationally designed reaction solution. Magnetic metals (such as $\mathrm{Co}, \mathrm{Fe}, \mathrm{Ni}$ and their alloys) with both electric and magnetic responds have been extensively studied as microwave absorbents. ${ }^{25-28}$ The silica-NiFeP composite system was employed as an example to investigate the effects of the component of the reaction solution, the reaction conditions and the shell thickness on the composition, structure and the electromagnetic properties of the DSCHPs. This work provides an new strategy to fabricate double or multi shell structured composite hollow particles with tailored shell composition and electromagnetic properties, which holds the potential to be extended to the controlled preparation of various double or multishell composite particles with robust hollow silica shell as support and various metal, alloy or metal oxides as functional shells.

\section{Experimental}

\section{Synthesis}

The water-glass solution is of industrial grade with solid content and module of $34 \%$ and 3.3, respectively. All the other reagents were of analytical grade and used as received.

\section{Preparation of sodium silicate hollow particles (SSHPs)}

The sodium silicate hollow particles (SSHPs) were produced through spray drying of the as-purchased water-glass solution. In a typical procedure, the water-glass solution was pulverized by a centrifugal atomizer with a rotate speed of $500 \mathrm{r} / \mathrm{s}$ (round per second), the nozzle inlet temperature is $300{ }^{\circ} \mathrm{C}$ and the feeding rate is $15 \mathrm{~mL} \mathrm{~min}{ }^{-1}$. At these experiment conditions, we can get ca. $50 \mathrm{~g}$ silicate hollow particles in $10 \mathrm{~min}$. In addition, various SSHPs with different size were obtained by adjusting the parameters of spray drying, such as solid content in the waterglass solution, inlet temperature, rotating speed and feeding rate.

\section{Preparation of activated silica hollow particles (ASHPs)}

The silicification and surface activation of the sodium silicate shell were realized simultaneously through a stepwise "coupling-sensitizing-activating" process to get activated silica hollow particles (ASHPs) whose surfaces were decorated with active sites.

Firstly, $10 \mathrm{~g}$ SSHPs were dispersed in $200 \mathrm{~mL}$ of ethanol solution containing $20 \mathrm{~g} \mathrm{~L}^{-1} \mathrm{KH} 550$ (3-aminopropyltriethoxy silane) in the coupling process. The suspension was stirred for $30 \mathrm{~min}$, then the hollow particles were filtered off, washed twice with ethanol and dried in a vacuum drying chamber at $120{ }^{\circ} \mathrm{C}$ for $4 \mathrm{~h}$. Subsequently, in the sensitization process, the particles after coupling treatment were dispersed in an acid solution containing $10 \mathrm{~g} \mathrm{~L}^{-1} \mathrm{SnCl}_{2}$ and $15 \mathrm{~mL} \mathrm{~L}^{-1}$ concentrated $\mathrm{HCl}$ (38 $\mathrm{wt} \%$ ), then stirred at $50{ }^{\circ} \mathrm{C}$ for $30 \mathrm{~min}$ and filtered off. Finally, the wet hollow particles after sensitization treatment were directly redispersed in a solution containing $2 \mathrm{~g} \mathrm{~L}^{-1} \mathrm{PdCl}_{2}$ and $15 \mathrm{~mL} \mathrm{~L}^{-1} \mathrm{HCl}$ (38 wt\%), stirred at $50{ }^{\circ} \mathrm{C}$ for $30 \mathrm{~min}$. Then the hollow particles were filtered off, washed twice with deionized water and ethanol (weight ratio $2: 1$ ) mixture solution and dried in a vacuum drying chamber at $120{ }^{\circ} \mathrm{C}$ for $12 \mathrm{~h}$. During the above mentioned three step treatment (especially in the sensitization process), the $\mathrm{Na}_{2} \mathrm{O}$ in the pristine sodium silicate hollow particles were leached out in the acidic reaction solution while the hollow spherical structure were well reserved, resulting in ASHPs with the surface decorated with $\mathrm{Pd}^{2+}$ active sites (for the catalyzed reduction of metal ions in the subsequent metallic shell assembly process).

\section{Preparation of double shell composite hollow particles (DSCHPs)}

The preparation of double shell composite hollow particles (DSCHPs) were carried out by directed assembly of magnetic metallic shells on the activated surfaces of the ASHPs. In situ chemical reduction and deposition of metal ions in well 
prepared aqueous reaction system (with the existence of the ASHPs) were employed for the directed assembly of magnetic metallic shells. The compositions of the reaction system and the reaction conditions for three different series of samples (S1$\mathrm{S} 3$, with different $\mathrm{Ni}^{2+} / \mathrm{Fe}^{2+}$ mole ratios in the reaction system) were listed in Table S1. $\dagger$ The loading amount (the weight of the ASHPs used in per liter of the reaction solution) of the ASHPs were controlled to be $10 \mathrm{~g}$. To get DSCHPs with different metallic shell thickness, the as obtained DSCHPs were used for the further assembly of metallic shells in the identical reaction system. Take S1 as an example, the DSCHPs obtained after 1, 2, 3 and 4 cycles of metallic shell assembly were labeled as S11, S12, S13 and S14 (similar nomination for S21-S24 and S31-S34). After 5 min reaction, the DSCHPs products were separated by magnetic separation, washed three times with deionized water and absolute ethanol, and dried at $60{ }^{\circ} \mathrm{C}$ in a vacuum drying chamber.

\section{Characterization}

The morphology and microstructures of the obtained samples at different stages were characterized using a field-emission scanning electron microscope (FE-SEM, Hitachi-S4800, Japan) and AxioImager A2m optical microscope. The energy dispersive X-ray (EDX) spectrum were obtained using Energy dispersive spectrometer Horiba. The phase structures were identified by $\mathrm{X}$ ray powder diffraction (XRD, D/max 2200PC, Rigaku, Japan), using $\mathrm{Cu} \mathrm{K} \alpha(\lambda=0.15406 \mathrm{~nm})$ radiation with a $2 \theta$ range from $10^{\circ}$ to $80^{\circ}$ and a scanning rate of $10^{\circ} \mathrm{min}^{-1}$. The X-ray photoelectron spectroscopy (XPS) spectrum were obtained in a PHI 5000 VerasProbe systems using an $\mathrm{Al} \mathrm{K} \alpha \mathrm{X}$-ray source and operating at $150 \mathrm{~W}$. The composition of metal shell was measured by Inductively Coupled Plasma (ICP) (Varian 710OES, Varian, American). The thermogravimetric (TG) analysis was carried out on a SETSYS Evolution TGA in the temperature range from room temperature to $900{ }^{\circ} \mathrm{C}$ with a heating rate of $5{ }^{\circ} \mathrm{C} \mathrm{min}^{-1}$. The size distribution of the samples were also measured by laser particle analyzer (Mastersizer 2000, Britain). The density of the samples were measured using gravimetric methods. The S parameters including S11, S12, S21, and S22 will be measured by a vector network analyzer (VNA, Agilent), over 2-18 GHz, using the coaxial-line method. A sample containing $30 \mathrm{wt} \%$ powders was pressed into a toroidal-shaped ring with an outer diameter of $7 \mathrm{~mm}$, an inner diameter of $3 \mathrm{~mm}$, and a thickness of $2 \mathrm{~mm}$ for electromagnetic parameter measurement, in which paraffin wax was used as the binder. Complex permeability and complex permittivity of the samples were calculated by software installed in Agilent VNA.

\section{Results and discussion}

The compositions of as-synthesized hollow microsphere samples during the three-step procedure were identified by XRD and EDX characterization. Fig. 1 show the XRD patterns of the as-prepared samples. Before the assembly of NiFeP shell, a broad peak with low intensity can be seen in the XRD patterns of both the SSHPs and ASHPs samples, indicating an

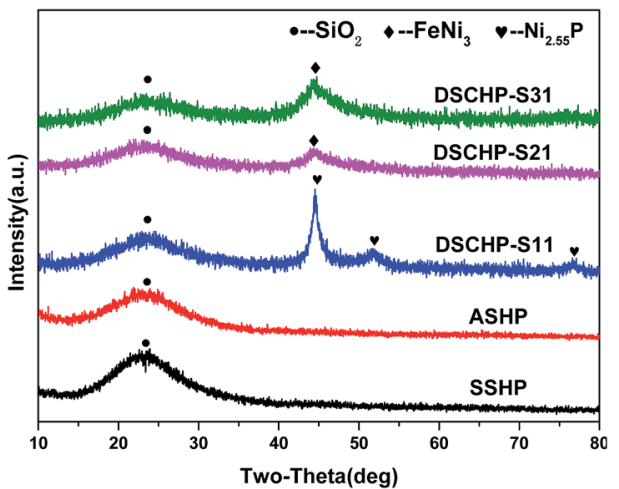

Fig. 1 XRD patterns of the SSHPs, ASHPs and different DSCHPs.

amorphous nature of the silicate and silica shells. ${ }^{29,30}$ For the DSCHPs obtained after NiFeP shell assembly, some additional peaks appeared on the XRD patterns of the as-obtained composite particles DSCHP-S1, DSCHP-S2 and DSCHP-S3, indicating the formation of metallic shells via electroless plating. Similar to the silicate and silica shells, the crystallization of the metallic shells is also on a low level, as indicated by the weak board XRD peaks. In addition, we also carried out the repetitive assembly of the metallic shells for four cycles (the samples were named as DSCHP-S11, DSCHP-S12, DSCHP-S13, DSCHP-S14 for 1, 2, 3 and 4 cycle(s) of NiP shell assembly, as well as DSCHP-S2 and DSCHP-S3, respectively).

With the increased FeNiP shell assembly cycle, the diffraction peaks of the metal shells became sharper while the broad peak for amorphous silica got weaker, which can be attributed to the increased metallic shell thickness and the improved crystallization (see Fig. S1a-c† for the dependence of the XRD patterns on the assembly cycle of the metallic shell for samples DSCHP-S1, for DSCHP-S2, DSCHP-S3, respectively). Fig. 2a is the EDX spectrum of the SSHPs obtained by spry drying, showing the presence of $\mathrm{Na}, \mathrm{O}$ and $\mathrm{Si}$ in the shell. Compared to the EDX spectrum of the SSHPs, some additional broad
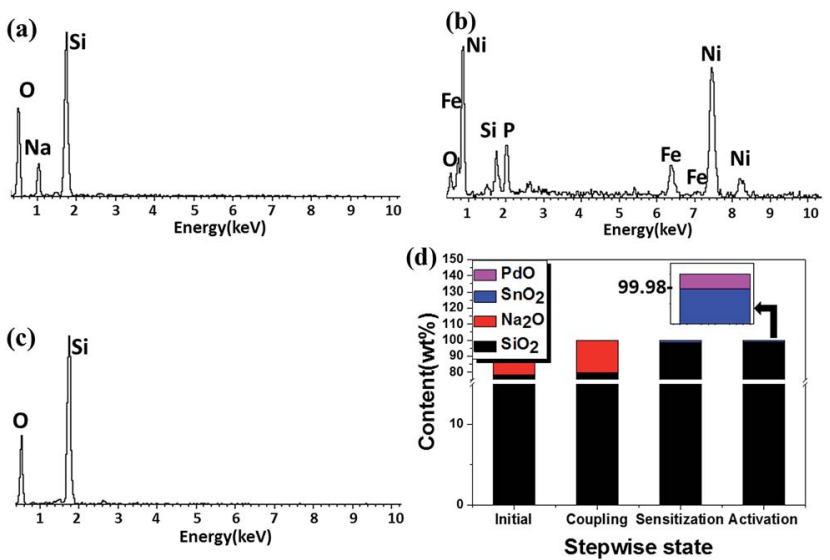

Fig. 2 EDX spectra of the as-obtained hollow particles (a) SSHPS, (b) DSCHPs, (c) ASHPs; and (d) the XRF data of the hollow particles at different reaction stage. The top-right inset is the enlarged figure of the XRF results for the hollow particles obtained after activation. 
diffraction peaks appeared for the DSCHPs obtained after metal shell assembly, which can be attributed to the NiFeP alloy shell (Fig. 2b). The codeposited metal is metastable, supersaturated alloy consisting of $\mathrm{P}$ atoms trapped between the $\mathrm{Ni}$ and $\mathrm{Fe}$ atoms. ${ }^{31}$ It should be noted that the EDX spectrum of DSCHPs indicates the absence of Na. It's interesting that the $\mathrm{Na}^{+}$was eliminated from the silicate shell, indicating the transformation of sodium silicate to silica $\left(\mathrm{NaSiO}_{3} \rightarrow \mathrm{SiO}_{2}\right)$ in the inner shell during the assembly of metallic shell. Fig. 2c reveals that, actually, the transformation of sodium silicate to silica occurred during the pretreatment with acid solution since no Na peaks in the EDX spectrum of ASHPs can be seen. To further confirm this speculation and find the variation trend of the sodium element, XRF (the X-ray fluorescence) analysis of the hollow particles obtained at different reaction stage was also carried out. As shown in Fig. 2d, during the three stepwise pretreatment (silane coupling, sensitization, activating), the content of Si increases while Na decreases to almost zero. There are no obvious changes in the composition of the pristine SSHPs after silane coupling (see also Fig. S2a $\uparrow$ for the EDX spectra). While after sensitization in acidic reaction solution, almost all the Na element were eliminated and no Na peaks can be detected in the EDX spectrum of the hollow particles at this stage (Fig. S2b $\dagger$ ). In the meantime, the content of $\mathrm{SiO}_{2}$ content increased remarkably to $98.50 \mathrm{wt} \%$. Finally, in the activation process (also in acidic atmosphere), the $\mathrm{Na}$ and $\mathrm{SiO}_{2}$ content changed slightly, indicating that the silicification occurred mainly in the sensitizing procedure of the pretreatment. We supposed that sodium silicate was hydrolyzed to silica because of the $\mathrm{HCl}$ used in the sensitizing and activating pretreatment, which provided an acid environment, ${ }^{32}$ as shown in eqn (1).

$$
\mathrm{Na}_{2} \mathrm{SiO}_{3}+2 \mathrm{HCl}=\mathrm{SiO}_{2}+2 \mathrm{NaCl}+\mathrm{H}_{2} \mathrm{O}
$$

The SSHPs with different size distribution can be obtained by controlling the parameter of spray drying, (see Fig. S $\uparrow \uparrow$ for the three samples with mean diameters of $17.15 \mu \mathrm{m}, 27.81 \mu \mathrm{m}$ and $35.92 \mu \mathrm{m}$, respectively), which opens an avenue to meet different application demands. Fig. S4 $\dagger$ shows the SEM images taken on the surfaces of the hollow particles at different stage of the pretreatment. The pristine SSHPs have rough surface with many canaliculus (Fig. S4a†), which may result from the uneven evaporation of water and the fast formation of silicate shell during high temperature spray drying. After silane coupling, the canaliculus disappeared and many small holes were formed on the surface (Fig. S4b $\dagger$ ), which may be attributed to the slow dissolution of silicate into water. After silane coupling treatment, the hollow particles exhibit hydrophobic properties due to the existence of aminopropyl as XPS spectra of N 1s shown in Fig. S5 $\uparrow \cdot{ }^{33}$ The hydrophobic layer were formed on the surface of the hollow particles which slowed down the dissolution of silicate. ${ }^{34-36}$ In the subsequent sensitization with $\mathrm{SnCl}_{2}$ in $\mathrm{HCl}$ solution, the hydrophobic layer can prevent the self-nucleation of newly formed silica phase (through acid hydrolyzation) and favor their nucleation and growth on the surface of the SSHPs (Fig. S4c $\dagger$ ). Then the subsequent activation (also in acidic atmosphere) can further smooth the surface and make the silica shell become dense (Fig. S4d†). In the meantime of the silicification, the surface sensitization with stannum (Fig. S6†) and activation with palladium (Fig. S7 $\dagger$ ) of the hollow particles were completed. ${ }^{37-39}$ Thus we could obtain a series of activated silica hollow particles (ASHPs) with different sizes.

The thermal stability of the as-obtained hollow particles (SSHPs and ASHPs) was characterized by thermogravimetric analysis (TGA) carried out in air flow with a heating rate of $5{ }^{\circ} \mathrm{C}$ $\min ^{-1}$. As shown in Fig. $\mathrm{S} 8, \uparrow$ the TG-DTA pattern of the SSHPs has an obvious endothermic peak at $350{ }^{\circ} \mathrm{C}$ resulting from the fusion of silicate, while that of the ASHPs has an continuous endothermic gradient with no change of mass due to transition of crystal phase (crystallization). To further confirm the improvement of thermostability at high temperature, calcinations of the SSHPs at $400{ }^{\circ} \mathrm{C}$ for $30 \mathrm{~min}$ and the ASHPs at a much higher temperature of $1300{ }^{\circ} \mathrm{C}$ for an elongated duration of 120 min were carried out. As shown in Fig. S9a, $\uparrow$ the SSHPs were collapsed and the hollow spherical morphology was lost even at lower temperature of $400{ }^{\circ} \mathrm{C}$, which made them unavailable for high temperature processing and application. Comparatively, the hollow spherical structure of the ASHPs (Fig. S9b $\dagger$ ) remained well during long time calcination at a much higher temperature, indicating a promising potential in high temperature application. Actually, well crystallized shells were formed after high temperature calcination. As is shown in Fig. S10, $\dagger$ XRD analysis reveals that after high temperature calcination, the ASHPs transformed into crystallized silica hollow particles (CSHPs) with the shells composed of $\alpha$-cristobalite. On the other hand, no new phase appeared after calcination of the ASHPs at $400{ }^{\circ} \mathrm{C}$. Therefore, it can be safely concluded that the amorphous silica oxide in the ASHPs hollow particles can successively transformed to crystalline $\alpha$-cristobalite with the hollow spherical structure well preserved, and hence a much broader application potential, especially in high temperature fields, can be expected.

Table S1 $\uparrow$ shows the composition of the reaction system and the reaction condition for NiFeP shell assembly with different mole ratio $\mathrm{Fe}^{2+} /\left(\mathrm{Fe}^{2+}+\mathrm{Ni}^{2+}\right)$. The morphology evolution of the hollow particles was studied by optical microscopy and FE-SEM observations of the hollow particles obtained at different reaction stages, as shown in Fig. 3 (the DSCHP-S2 series are taken as example). It can be seen obviously seen that the optical microscopy images of the SSHPs (Fig. 3a) and ASHPs (Fig. 3b) samples are transparent and glossy, indicating the high uniformity and smoothness of the shell. Moreover, attributed to the high transparency, the spherical structure with thin shell thinness can also be seen clearly from the optical microscopy images, which is in good accordance with the SEM images taken on the fragment of the hollow particles shown in Fig. 4, different from the SSHPs and ASHPs, the optical microscopy image of the DSCHPs (Fig. 3c) exhibits no transparency, indicating the assembly of nontransparent metallic shells on the ASHPs. Moreover, the metallic shells of the DSCHPs were also found to be smooth and glossy, together with the above mentioned nontransparency, the uniform, smooth and integrated metallic shells can be well verified. Fig. 3d depicts 


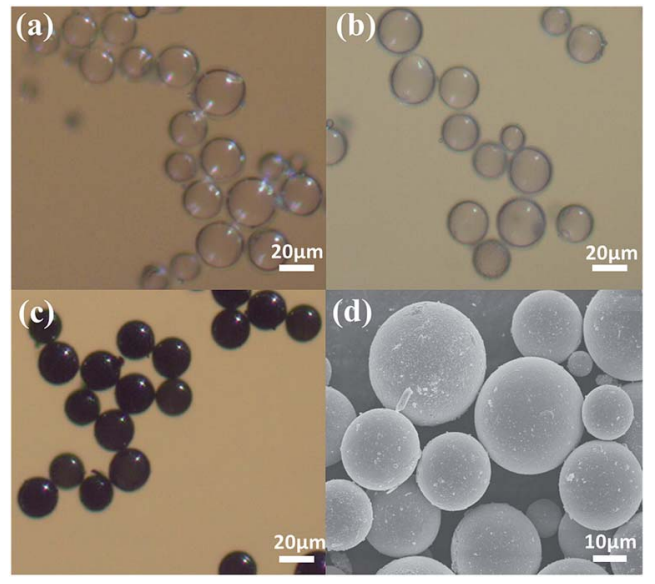

Fig. 3 Optical microscopy images of the as obtained hollow particles (a) SSHPs, (b) ASHPs, (c) DSCHPs; (d) SEM image of DSCHPs.

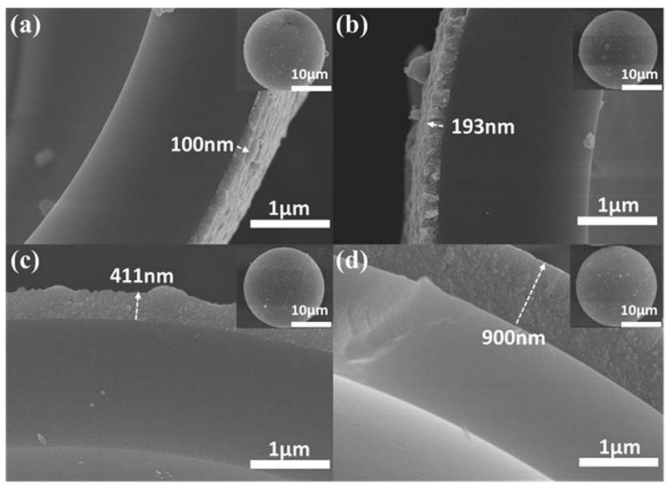

Fig. 4 SEM images of DSCHP-S21 (a), DSCHP-S22 (b), DSCHP-S23 (c), and DSCHP-S24 (d) with increased metallic shell assembly cycles. The inset in each panel is the SEM images of the full view of a single hollow particle of the corresponding sample.

a panoramic image of the DSCHPs, which reveals a continuous and uniform metallic shell assembly on the ASHPs. Various DSCHPs with different shell thicknesses were obtained through the process of "seed and assembly" several times (the previously formed metallic shells can serve as seeds for the next cycle of assembly). As can be seen in Fig. 4 (a-S21, b-S22, c-S23, d-S24) the metallic shell gets increasingly thicker (from $100 \mathrm{~nm}$ to $900 \mathrm{~nm}$, with no obvious interfaces between those form in different cycles) with the increased assembly cycle number. Similar shell thickness variation was also found in the DSCHPS1 and DSCHP-S3 series (Fig. S11 and S12 $\dagger$ ). Another experiments (not listed in this article) have been done with changing the concentration of the reactants to get different thickness of metallic shell. But unfortunately a too fast reaction speed resulting from raised metal ion concentration inevitably leads to nonuniform shells, and even results in homogeneous nucleation to form isolated metallic particles. Therefore, it is more reliable to adjust the thickness of the metallic shell by changing the cycle number rather than the concentration of the reactants. The real density of the as-obtained DSCHPs were measured by gravimetric methods. As shown in Fig. 5, the real

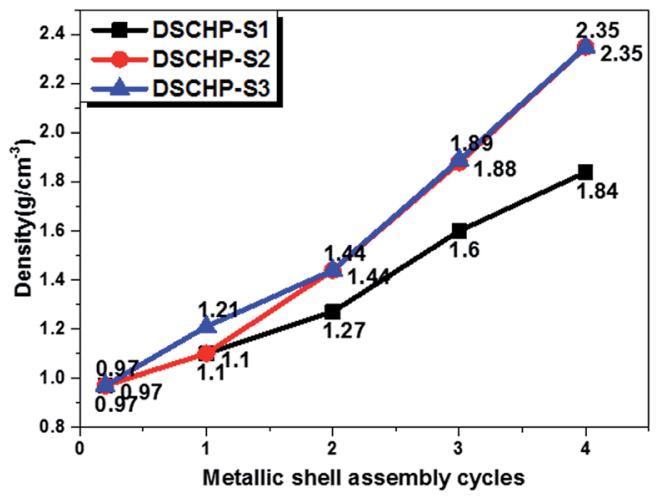

Fig. 5 The dependence of density on the metallic shell assembly cycle of the three series of samples. The starting point with assembly cycle number of zero stands for the density of the activated ASHPs $\left(0.97 \mathrm{~g} \mathrm{~cm}^{-3}\right)$.

density of the as-obtained DSCHPs increases monotonously with the increased assembly cycle number, which can be attributed to the increased thickness of the metallic shell and the reduced hollow interior proportion in the overall particle. Moreover, it should be noted that the densities of these DSCHPs (1.1-2.35 $\mathrm{g} \mathrm{cm}^{-3}$ ) are much lower than those of the bulk iron $\left(7.87 \mathrm{~g} \mathrm{~cm}^{-3}\right)$ or nickel $\left(8.90 \mathrm{~g} \mathrm{~cm}^{-3}\right) .{ }^{40}$

The EDX element maps of an individual DSCHP are shown in Fig. S13. $\uparrow$ The inner $\mathrm{SiO}_{2}$ shell can clearly observed in the violet core region indicated by a yellow circle, while the $\mathrm{Ni}$ (red colored), Fe (blue colored) and $\mathrm{P}$ (yellow colored) can be detected in the whole particle's regions, which means that the metallic shell coated on surface of $\mathrm{SiO}_{2}$ hollow particles is integrated and uniform. As the outer metallic shell is assembled on the inner silica shell, the colored regions of $\mathrm{Ni}, \mathrm{Fe}$ and $\mathrm{P}$ are larger than those of silica and oxygen. To further illustrate the composite shelly structure, EDX element mapping and line scan analysis on a fragment of the composite shell were also carried out, as shown in Fig. 6. The composite double shell structure can be seen clearly form the SEM image taken on the fragment. Moreover, EDX element mappings shown dissociated in Fig. 6b-e clearly reveal that the inner shell is composed of silicon and oxygen, while the iron, nickel and phosphorus are

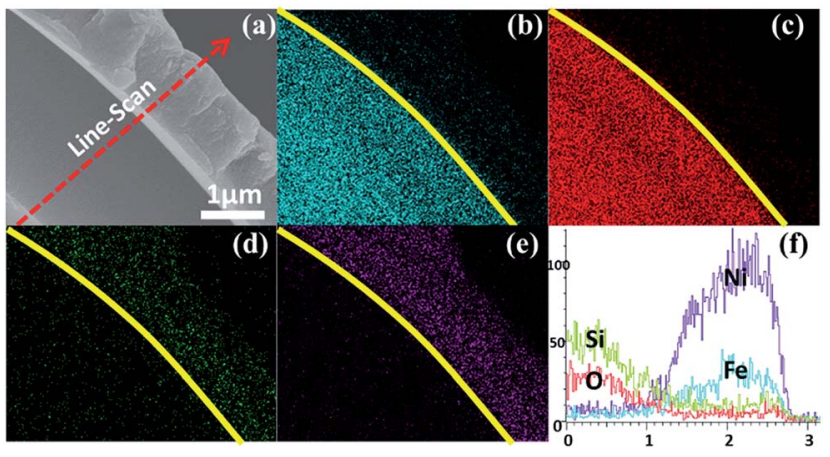

Fig. 6 SEM (a) image, the corresponding EDX element mapping of (b) $\mathrm{Si}$, (c) $\mathrm{O}$, (d) Fe and (e) Ni, and line-scan analysis (f) taken on a fragment of the as-obtained DSCHP-S2. 
from the outer metallic shell, which is further confirmed by the results of the line scan analysis shown in Fig. 6f.

As is reported previously, a freshly formed surface is usually unstable because of its high surface energy. For liquids or surfaces with sufficient plastic flow, the excess energy can be dissipated (to some degree) by spontaneously reducing the total interfacial area through formation of spherical drops. ${ }^{41}$ It can illustrate the formation of high sphericity degree and smooth surface of the SSHPs in the spray drying process. When the droplets went into the drying chamber with relatively high temperature, a dry shell was formed at first on the surface of the droplet by fast evaporation of water. As the evaporation process went on, the liquid water will transfer to the preformed dry shell and transpired, leaving the solute to deposit on the preformed dry shell and finally give birth to well defined hollow spherical particles. To further reduce the surface energy, the clean solid surface still has a strong driving force to adsorb materials. As a result, when mixed with the silane solution in the coupling process, the adsorption interaction between the surface of the SSHPs and silane molecules will occur. Specially in the case of silicate surfaces and the existence of silicon hydroxyl in the hydrolyzed coupling agent, the adsorption may also be realized through chemical bonds. As is reported previously, many hydroxyls exist on the surfaces of oxides, which can be employed for the modification of these surfaces. ${ }^{42}$ When mixed with molecules containing hydroxyl, sulfhydryl, carboxyl, et al., the surface hydroxyls will interact with these groups to form hydrogen bonds. With a further eliminating of water trough heat treatment, stronger covalent bonds will be formed. In order to initiate the reduction of metal ions and realize the in situ growth and assembly of metal directly on the hollow particles, activation of the particle surface will be necessary involving the introduction of catalytic seeds. In our case, surface activation of the sodium silicate shell were easily realized in acid solution in two steps on the premise of the former silane coupling. Firstly, the SSHPs after silane coupling were placed into $\mathrm{SnCl}_{2}$ acid solution to absorb $\mathrm{Sn}^{2+}$ sensitizing layer on the surface. ${ }^{43}$ At the same time, the transformation of sodium silicate to silica $\left(\mathrm{Na}_{2} \mathrm{SiO}_{3} \rightarrow \mathrm{SiO}_{2}\right)$ in the inner shell occurred, and $\mathrm{Na}^{+}$was dissociated from the silicate shell. According to Iler, ${ }^{44}$ when the $\mathrm{pH}$ of solution increases above the isoelectric point of silica ( $\mathrm{pH} \mathrm{2-3),} \mathrm{the} \mathrm{polycondensation} \mathrm{rate} \mathrm{of} \mathrm{aqueous} \mathrm{silicate}$ becomes more and more rapid. On the contrary, the formation of soluble silicic anions inhibits the polycondensation degree for $\mathrm{pH}$ above 9. Therefore, if an acid is added to lower the $\mathrm{pH}$ of an alkaline silicate solution to, for example, 7, the polycondensation is triggered with a high rate before the desired $\mathrm{pH}$ is reached. ${ }^{30}$ When alkaline silicate hollow particles were added to an acid solution that contains enough acid to stabilize the $\mathrm{pH}$ around 2, the hollow particles acted as microreactors. The KH550 was chosen with the aim of avoiding dissolving and polycondensation of silicate shell before the $\mathrm{pH}$ is reached at which the polycondensation has to occur, which is also very important for absorption of $\mathrm{Sn}^{2+}$ on the surface of $\mathrm{SiO}_{2}$ particles. The $\mathrm{pH}$ of reaction environment of microreactors can be increased from the acidic outer to alkaline inner shells. At first, strong acidic fought back strong alkaline, silicification didn't happen. Whenever and wherever getting to the proper $\mathrm{pH}$, the silicification proceeded layer by layer slowly. Thus silicification completed from outer to inner. At the same time, the $\mathrm{Na}^{+}$ migrated from shells to the aqueous solution, because of different concentration between hollow particles and aqueous solution based on Fick's diffusion law. ${ }^{45}$ Thus silica hollow particles coated with tin sensitizing layer were obtained. Subsequently the silica hollow particles were immersed by $\mathrm{PdCl}_{2}$ solution to introduce palladium onto the tin sensitizing layer. The simple reaction $\mathrm{Sn}^{2+}+\mathrm{Pd}^{2+}>\mathrm{Sn}^{4+}+\mathrm{Pd}^{0}$ took place to make the surface catalytically active. ${ }^{46}$ Osaka et al. reported that large $\mathrm{Pd}-\mathrm{Sn}$ colloidal particles with their lower surface area: mass ratios, are less prone to oxidation are required for high catalytic activity. ${ }^{47}$ On the other hand, the presence of $\mathrm{Pd}$ in higher oxidation states limits the autocatalytic activity of the activated substrates. ${ }^{48,49}$ It's good to reduce the palladiumdecorated hollow particles with reducing agent before metal assembly. Then the palladium-decorated hollow particles were placed into alkaline solution containing $\mathrm{Ni}^{2+}, \mathrm{H}_{2} \mathrm{PO}^{2-}$, catalytic reduction happened. $\mathrm{Pd}$ acted as the catalytically activated sites while $\mathrm{H}_{2} \mathrm{PO}^{2-}$ as a reducing agent, Ni deposited on the activated sites on the surface of particles. The deposited clusters of metal atoms then catalyze further metal deposition on the hollow particles to obtain thickness metal shells. In brief, the growth of metallic shell is initialized by the Pd seeds in the starting stage and then continue subsequently through a self-catalyzed process. Above all, it means that we get a way to obtain silica hollow particles with much more chemical durable and thermostable properties through the spray drying using water glass solution as precursor solution and surface treatment in an acid solution, which is significantly valuable for the template method used in the high temperature treatment. Afterwards, light weight (1.1-2.35 $\mathrm{g} \mathrm{cm}^{-3}$ ) DSCHPs with the outer (second) shell composed of various metals were fabricated on the surface of ASHPs through in situ chemical reduction of metal ions. A related schematic illustration of the overall stepwise formation of the DSCHPs is depicted in Fig. 7. It should be noted that the new strategy reported here holds the potential to be extended to the controlled preparation of various double or multishell composite particles with robust hollow silica as support and various metal, alloy as functional shells. So far, we have successively assembled metallic cobalt and nickel-cobaltphosphorus alloy shells on our silica shell to prepare $\mathrm{SiO}_{2}-\mathrm{Co}$ and $\mathrm{SiO}_{2}-\mathrm{NiCoP}$ DSCHPs, as shown in Fig. S14 and S15, $\dagger$ respectively.

Generally, the values of real and imaginary parts of electromagnetic parameters respectively represent the energy storage and inner dissipation capability of the incident electromagnetic wave. ${ }^{5}$ The electromagnetic parameters were measured by vector network analyzer (VNA) of paraffin-composites containing $30 \mathrm{wt} \%$ of the DSCHPs in the frequency of $2-18 \mathrm{GHz}$. The measured DSCHPs samples have approximately equal density $\left(1.88 \mathrm{~g} \mathrm{~cm}^{-3}\right)$ but different mole ratio of $\mathrm{Ni} / \mathrm{Fe}$ in the metal shells (DSCHP-S14 no Fe, DSCHP-S23 6.67 and DSCHP-S33 $\sim 5.53$, measured by ICP). When they get the same density, the mass contents of assembly metal shells on the ASHPs are also equal. It is an advisable way to investigate the electromagnetic 


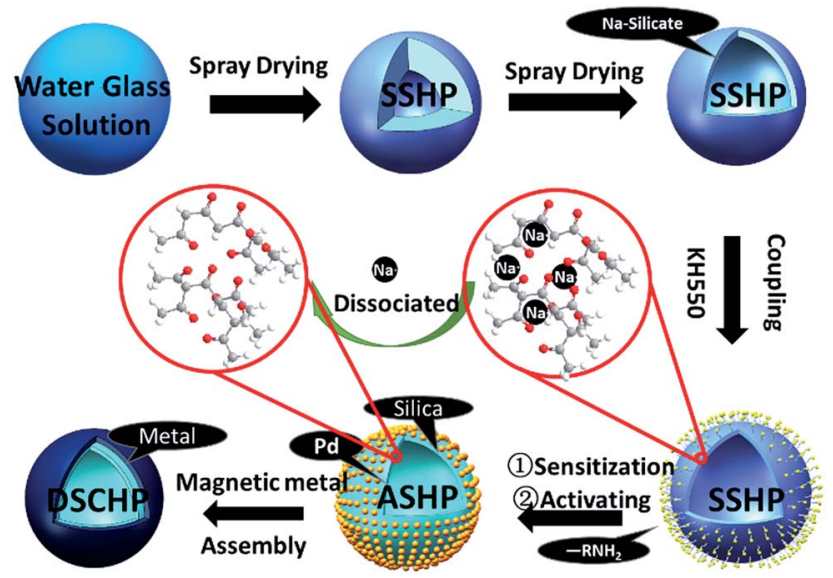

Fig. 7 Schematic illustration of the stepwise formation process of the DSCHPS.

parameters at the same density instead of the same thickness, which can eliminate the influence of different content of efficient filling absorbers. The thickness also have a great effect on electromagnetic parameters, which will be discussed in followup work. The complex permittivity $\left(\varepsilon_{\mathrm{r}}=\varepsilon^{\prime}-\mathrm{i} \varepsilon^{\prime \prime}\right)$ and permeability $\left(\mu_{\mathrm{r}}=\mu^{\prime}-\mathrm{i} \mu^{\prime \prime}\right)$ of paraffin-based composites are the fundamental physical quantities for determining the microwave properties of composites. Because the paraffin wax has little effect on the transmission of electromagnetic microwave, ${ }^{25}$ the measured electromagnetic parameters can reflect the nature of the DSCHPs.

As shown in Fig. S16a and $\mathrm{b}, \dagger$ the values of $\varepsilon^{\prime}$ and $\varepsilon^{\prime \prime}$ for the DSCHPs samples decrease with the increased iron ratio. All of the three samples have high dielectric constants because of the high conductivity of the metal shells. In addition, $\mathrm{SiO}_{2}$ is an insulator, which results in the formation of space charge polarization on the interfaces between metal shells and insulator $\mathrm{SiO}_{2}$ shells in the electromagnetic field. ${ }^{\mathbf{5 0} 51}$ In general, the dielectric loss, represents by the imaginary permittivity $\left(\varepsilon^{\prime \prime}\right)$, can be attributed to natural resonance, electron polarization and Debye dipolar relaxation. ${ }^{52}$ The as-obtained hollow particles with NiP shells exhibit a much higher dielectric constant $\varepsilon^{\prime}$ (10.03-38.98, Fig. S16a $\dagger$ ) and dielectric loss $\varepsilon^{\prime \prime}$ (10.51-20.93, Fig. S16b $\dagger$ ) than the other two samples with NiFeP shells. It is can be seen clearly that, with the existence of iron in the metallic shell, the values of $\varepsilon^{\prime \prime}$ exhibit a sharp decline. ${ }^{53}$ The dielectric constant decreases slightly with decreased mole ratio of $\mathrm{Ni} / \mathrm{Fe}$ in the metal shells. The values of $\varepsilon^{\prime}$ of the three samples decrease monotonously with the increased frequency. On the contrary, the curve of $\varepsilon^{\prime \prime}$ for DSCHP-S14 have three conspicuously broad peaks for high-frequency resonance from $6 \mathrm{GHz}$ to $18 \mathrm{GHz}$, which can be interpreted by electron polarization. Some weak resonance peaks at $10 \mathrm{GHz}$ can also be found for DSCHP-S23 and DSCHP-S33. It is generally believed that the complex permittivity is sensitively increased with the improved conductivity due to the enhanced space charge polarization. ${ }^{\mathbf{8 5 4}}$ According to the free electron theory, ${ }^{55}$ smaller $\sigma$ value leads to lower $\varepsilon^{\prime \prime}$ value $\left(\varepsilon^{\prime \prime}=\sigma /\left(2 \pi \varepsilon_{0} f\right)\right.$, where $\varepsilon^{\prime \prime}$ is the imaginary part of the complex permittivity, $\sigma$ is the conductivity, $\varepsilon_{0}$ is the free space permittivity $\left(8.854 \times 10-12 \mathrm{~F} \mathrm{~m}^{-1}\right)$, and $f$ is the frequency, respectively.). Therefore, the higher $\sigma$ value of $\mathrm{Ni}$ (bulk $\mathrm{Ni} \sim 1.43$ $\left.\times 10^{7} \mathrm{~S} \mathrm{~m}^{-1}\right)$ and bulk Fe $\left(r \sim 1.04 \times 10^{7} \mathrm{~S} \mathrm{~m}^{-1}\right.$, respectively $)$ leads to higher values of dielectric constant of DSCHP-S14 (NiP shell) than DSCHP-S23 and DSCHP-S33 (NiFeP alloy shell). As shown in Fig. 8, it can be seen that the conductivity decreases with the increased Fe ratio, which further confirms the above conjecture. On the other hand, the charge migration happens in the conductive metal shells rather than the insulator $\mathrm{SiO}_{2}$ shells, which gives rise to the accumulation of charges and the formation of large dipoles at the interfaces. ${ }^{50}$ When Fe ions replace $\mathrm{Ni}$ ions, distortion took place and lattice constant was increased, leading to changes of the magnetic properties. Meanwhile, due to the smaller amount of hopping electrons between $\mathrm{Ni}$ and $\mathrm{Fe}$ on the octahedral sites, the permittivity became low, so the interfacial polarization and intrinsic electric dipole polarization arose, ${ }^{56}$ which was also favorable for impedance matching. Many previous works $s^{57,58}$ have shown that a moderate conductivity is favorable for improving the microwave absorption abilities. However, a rather high electrical conductivity is disadvantageous to electromagnetic loss in terms of the inferior impedance match between absorbing layer and the free space, result in the occurrence of skin effect and enhanced surface reflection of the incident electromagnetic wave. $^{59}$

As shown in Fig. S17a, $\uparrow$ both DSCHP-S23 and DSCHP-S33 possess higher $\mu^{\prime}$ values $\left(\mu^{\prime}>1\right)$ than DSCHP-S14. It can be found that there is an obviously wide resonance peak at a high frequency range (9-17 GHz) for DSCHP-S33 due to ferromagnetic strong uniaxial anisotropy field. On the other hand, no conspicuous differences are observed in values of the real permeability $\mu^{\prime \prime}$ below $13 \mathrm{GHz}$ with the increased Fe ratio. But above $13 \mathrm{GHz}$, the $\mu^{\prime \prime}$ value (Fig. S17b $\dagger$ ) for DSCHP-S33 gets much higher than those of another two samples. It is well known that the magnetic loss mainly originates from eddy current effects, hysteresis loss and residual loss. ${ }^{\mathbf{6 0 , 6 1}}$ The eddy current loss is correlated with the electric conductivity $(\sigma)$ and diameter $(d)$, which is also called skin-effect criterion. ${ }^{62}$ If magnetic loss originates from eddy current effect, the values of $\mu^{\prime \prime}\left(\mu^{\prime}\right)^{-2} f^{-1}$ should be constant with varying frequency between 2 and $18 \mathrm{GHz} .{ }^{63}$ Fig. 9 shows that the values of $\mu^{\prime \prime}\left(\mu^{\prime}\right)^{-2} f^{-1}$ for all

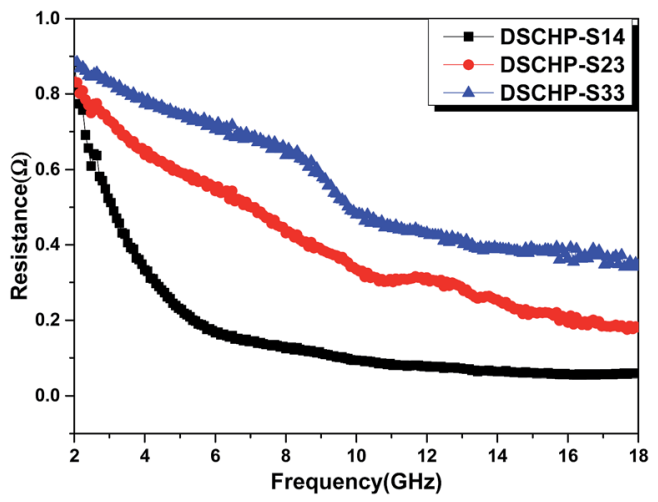

Fig. 8 The resistance ( $r$ ) of DSCHP-S14 (black curve), DSCHP-S23 (red curve) and DSCHP-S33 (blue curve). 


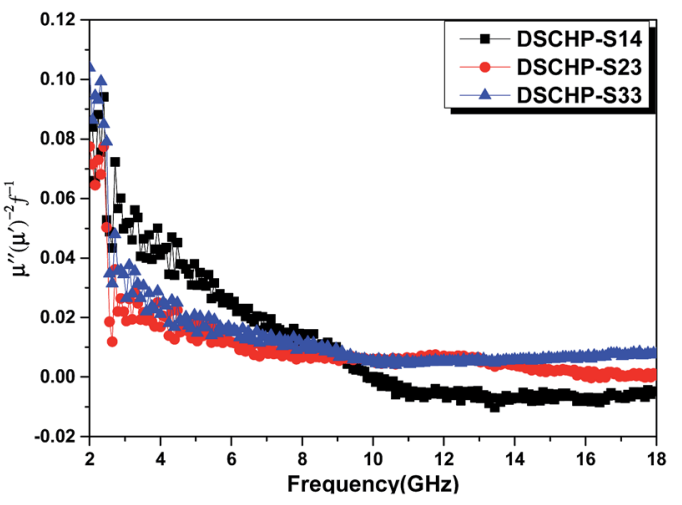

Fig. 9 The values of $\mu^{\prime \prime}\left(\mu^{\prime}\right)^{-2} f^{-1}$ of DSCHP-S14 (black curve), DSCHPS23 (red curve) and DSCHP-S33 (blue curve) as a function of frequency

of the three samples vary obviously with the increased frequency, indicating that the eddy current loss is suppressed. The hysteresis loss is negligible in weak applied field..$^{25}$ Therefore, the magnetic loss mainly arises from the residual loss, such as natural resonance, exchange resonance and domain wall displacement loss. The domain wall displacement loss occurs in the $\mathrm{MHz}$ range. ${ }^{64}$ Based on the Aharoni's theory, ${ }^{65}$ the resonance peaks at a low frequency range around $6 \mathrm{GHz}$ should belong to natural resonance, while the resonance peaks at high frequency (11 GHz and $13 \mathrm{GHz}$ for DSCHP-S23 and DSCHP-S33) correspond to the exchange resonance, ${ }^{6,67}$ as show in Fig. S17a. $\uparrow$ But for DSCHP-S33, the values of $\mu^{\prime \prime}\left(\mu^{\prime}\right)^{-2} f^{-1}$ are approximately same between 10 and $17 \mathrm{GHz}$, which means that the eddy current loss could also contributes to the magnetic loss at high frequency. ${ }^{68}$

In addition, the dielectric loss tangent and magnetic loss tangent are usually used to describe electromagnetic loss capacity. The dielectric loss tangents $\left(\tan \delta_{\varepsilon}=\varepsilon^{\prime \prime} / \varepsilon^{\prime}\right)$ and magnetic loss tangents $\left(\tan \delta_{\mu}=\mu^{\prime \prime} / \mu^{\prime}\right)$ of the metal-silica composites hollow particles are shown in Fig. S18. $\dagger$ It can be seen that the $\tan \delta_{\varepsilon}$ of DSCHP-S14 are much higher than the other two samples, especially in high frequency range. The values of $\tan \delta_{\mu}$ are about the same in low frequency range of 2$9 \mathrm{GHz}$ for all the three samples while in higher frequency range (9-18 GHz), the values of DSCHP-S33 show an obvious increase with the increased frequency. Interestingly, the values of $\tan \delta_{\varepsilon}$ for three samples are higher than $\tan \delta_{\mu}$, indicating that dielectric loss makes a major contribution to the electromagnetic loss. ${ }^{60,69}$ The attenuation constant is calculated using the follow equation: ${ }^{70}$

$$
\alpha=\frac{\sqrt{2}}{c} \pi f \sqrt{\left(\mu^{\prime \prime} \varepsilon^{\prime \prime}-\mu^{\prime} \varepsilon^{\prime}\right)+\sqrt{\left(\mu^{\prime \prime} \varepsilon^{\prime \prime}-\mu^{\prime} \varepsilon^{\prime}\right)^{2}+\left(\mu^{\prime} \varepsilon^{\prime \prime}+\mu^{\prime \prime} \varepsilon^{\prime}\right)^{2}}}
$$

where $f$ is the electromagnetic wave frequency and $c$ is the velocity of light. The attenuation constant $\alpha$ determines the attenuation properties of the composite materials. It is mainly dominated by the permittivity and permeability. As shown in Fig. 10, it can be observed that the attenuation constants of the three samples display a similar trend as the dielectric loss

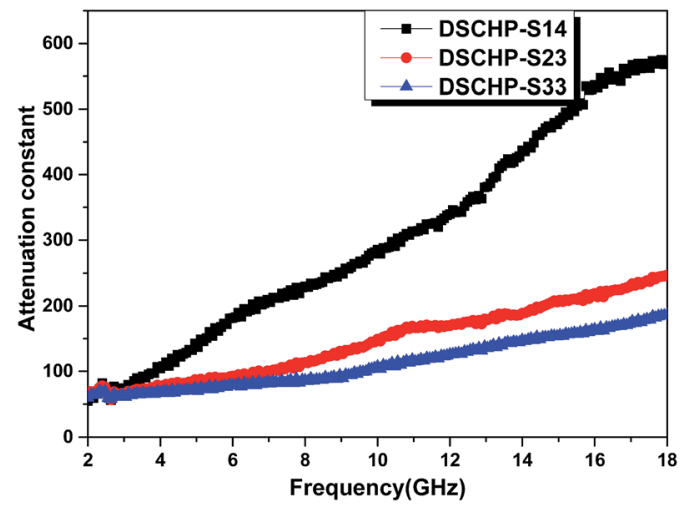

Fig. 10 Frequency dependences of the attenuation constant of DSCHP-S14 (black curve), DSCHP-S23 (red curve) and DSCHP-S33 (blue curve).

tangents. The values of attenuation constant for DSCHP-S14 are much larger than the other two samples with Fe deposited in the metallic shell. However, it is well known that the excellent electromagnetic wave absorption are strongly dependent on the efficient complementarities between the relative permittivity and permeability. ${ }^{71}$ The much higher attenuation constants of DSCHP-S14 compared with the other two samples, may not necessarily results in better electromagnetic wave dissipation, probably due to its worse impedance match and the increased reflection thereof. ${ }^{72}$

In order to further study the microwave absorption properties of metal-silica double shell composite hollow particles, we calculate the reflection losses (RL) based on the electromagnetic parameters in former figures. For a single-layer absorber baked by a metal backplane, as shown in Fig. S19a, $\dagger$ the RL of the samples can be calculated from the complex permittivity and complex permeability according to the transmit line theory. ${ }^{73}$

$$
\begin{gathered}
\operatorname{RL}(\mathrm{dB})=20 \log \left|\frac{Z_{\text {in }}-1}{Z_{\text {in }}+1}\right| \\
Z_{\text {in }}=\sqrt{\frac{\mu_{\mathrm{r}}}{\varepsilon_{\mathrm{r}}} \tanh \left[\mathrm{i}\left(\frac{2 \pi}{c}\right) f d \sqrt{\mu_{\mathrm{r}} \varepsilon_{\mathrm{r}}}\right]}
\end{gathered}
$$

where $Z_{\text {in }}$ is the normalized input impedance, $d$ is the thickness of the absorb layer, $c$ is the velocity of electromagnetic wave in vacuum, and $\mu_{\mathrm{r}}$ and $\varepsilon_{\mathrm{r}}$ are the relative complex relative permeability and permittivity, respectively. The thickness and the filling percentage of the samples usually are the important parameters considering the intensity and bandwidth for the best reflection loss. To clarify the influence of the mole ratio of $\mathrm{Ni} / \mathrm{Fe}$ in the metallic shells on the microwave absorbing performance, the calculated reflection loss curves of the DSCHP-S14, DSCHP-S23, and DSCHP-S33 with different samples thickness at the filling content of $30 \%$ are shown in Fig. 11. Fig. 11 shows the curves of the reflection loss versus frequency of the paraffin-DSCHPs composites. The maximum reflection loss of the DSCHP-S14 is $7.53 \mathrm{~dB}$ (absolute value, similarly hereinafter) at $4.24 \mathrm{GHz}$ with a thickness $3 \mathrm{~mm}$, as shown in Fig. 11a. In comparison with DSCHP-S14, the other 
two samples (DSCHP-S23 and DSCHP-S33) possess much lower maximum reflection loss, indicating better microwave absorption performance. As shown in Fig. 11b, for DSCHP-S23, the maximum reflection loss is $19.10 \mathrm{~dB}$ at $6.8 \mathrm{GHz}$ with a thickness $3 \mathrm{~mm}$, which decreases with the decreased thickness. However, in the meantime, the effective absorption bandwidth (defined as the frequency range in which the RL value is lower than -10 $\mathrm{dB}$, indicating only $10 \%$ of the microwave energy is reflected while $90 \%$ is absorbed) gets broader. But a nearly reflection loss of $16.46 \mathrm{~dB}$ at $15.44 \mathrm{GHz}$ with broader range frequency $3.22 \mathrm{GHz}$ effective absorption bandwidth for thin thickness $1.5 \mathrm{~mm}$. Obviously, as the ratio of Ni/Fe is decreased to 5.53, the DSCHPS33 sample exhibits stronger absorption intensity $(45.92 \mathrm{~dB}$ at 15.92 GHz with a thickness of $1.5 \mathrm{~mm}$ ) and broader effective absorption bandwidth (Fig. 11c), indicating a better potential as high efficient microwave absorbent (compared with DSCHP-S14 and DSCHP-S23). To give a more visualized depiction of the microwave absorption properties of sample DSCHP-S33, a three-dimensional diagram of the dependence of RL on absorbing layer thickness and frequency was mapped, as shown in Fig. 11d. It can be seen from the contour map that the yellow shade area for RL value higher than $10 \mathrm{~dB}$ covers a wide frequency range from 3.5 to $18 \mathrm{GHz}$ with the thickness range 1$5.5 \mathrm{~mm}$. In addition, as is shown by blue shade area, the strong attenuation peak shifts to lower frequency range and another red shade area $(\mathrm{RL}<5 \mathrm{~dB})$ appear in the high frequency range with increased thickness. This phenomenon can be explained using the quarter-wavelength cancellation model. ${ }^{69}$ In the quarter-wavelength cancellation model, the incident and reflected waves in the absorbers are out of phase by $180^{\circ},{ }^{58}$ which induces the reflected waves totally extincted on the absorberfree space interface and leading to an emerging attenuation peak. In fact, some similar absorbers are hardly obtained with excellent electromagnetic absorption. Moreover, in addition to the low particle density, our DSCHPs also possess advantages in low dosage and absorber layer thickness when employed as candidates for electromagnetic parameter conditioning agents.
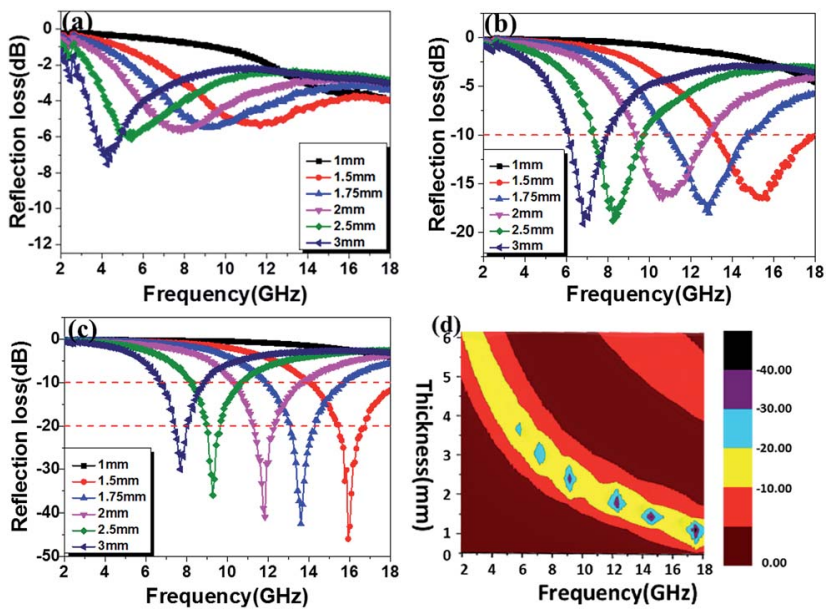

Fig. 11 The reflection loss (RL) of (a) DSCHP-S14, (b) DSCHP-S23 and (c) DSCHP-S33 with different thickness, (d) contour map of the DSCHP-S33 sample for RL > 10 dB, 90\% microwave absorption.
As can be seen from Table $\mathbf{S} 2, \dagger$ compared with the absorber layers prepared using some previously reported composite hollow structures, those prepared using our DSCHPs hold the lowest dosage and layer thickness, while exhibit strong microwave absorbing intensity and wide effective absorbing bandwidth. This opens an avenue to reduce the weight of microwave absorbing coatings or skin materials by the triplex synergism, namely decreasing the layer thickness, the particle density and the dosage of electromagnetic parameter conditioning agents simultaneously.

To give a further illustration of the electromagnetic behaviors influenced by the codeposition of NiFe, the power balance of the electromagnetic wave when passing through the paraffinDSCHP composites with a thickness of $2 \mathrm{~mm}$ were studied. ${ }^{74}$ The reflectance coefficient $(R)$, transmittance coefficient $(T)$ and absorption coefficient $(A)$ of electromagnetic wave were calculated in terms of scattering parameters $\left(S_{11} / S_{22}\right.$ and $\left.S_{12} / S_{21}\right)$ by the following equations: ${ }^{75}$

$$
\begin{gathered}
T=\left|S_{12}\right|^{2}=\left|S_{21}\right|^{2} \\
R=\left|S_{11}\right|^{2}=\left|S_{22}\right|^{2} \\
A=1-T-R
\end{gathered}
$$

Fig. 12 shows the reflectance coefficient $(R)$, transmittance coefficient $(T)$ and absorption coefficient $(A)$ of the three samples. It can be clearly seen that the DSCHP-S14 possesses the highest reflectance coefficient $(R)$ values (Fig. 12a-black curve). The codeposition of $\mathrm{Fe}$ and $\mathrm{Ni}$, leads to lower reflectance coefficient $(R)$ values than pure $\mathrm{Ni}$ deposition due to the decrease of conductivity (Fig. 8), which further confirms that the high conductivity induces more reflection on the surface. ${ }^{76} \mathrm{As}$ shown in Fig. S17 and S18, $\dagger$ the DSCHP-S14 with only Ni coated has the highest permittivity while the permeability are too small, which means that it possesses typical dielectric loss. For DSCHP-S23 and DSCHP-S33, they have improved magnetic loss with the increased iron ratio, which could have a good favor to the impedance match. ${ }^{1}$ In other words, the reflection of electromagnetic wave at the surface becomes low, while more electromagnetic wave entering the absorbers to be attenuated. As discussed previously, the heterogeneous phase assembly shells improve interfacial polarization and intrinsic electric dipole polarization, which means have a good effect for absorption coefficient (A) values (Fig. 12b-blue curve). Thus the development of reflection loss mainly comes from the absorption of electromagnetic materials itself, which induces the max intensity of reflection loss of samples (DSCHP-S23) increased with the thickness increased (Fig. 11b). With more Fe ions replace Ni ions, the absorption coefficient $(A)$ values (Fig. 12bblue curve) of DSCHP1-S33 decreased while transmittance coefficient $(T)$ values (Fig. 12c-red curve) increased compared with DSCHP-S23. It's interesting found that DSCHP-S14 and DSCHP-S33 have the nearly equal absorption coefficient values from 7.2 GHz to $13.1 \mathrm{GHz}$, which can be explained by Debye dipolar relaxation process resulting from the same number of core-core semicircle, ${ }^{2}$ as Fig. S20 $\dagger$ shown. But above $13.1 \mathrm{GHz}$, 

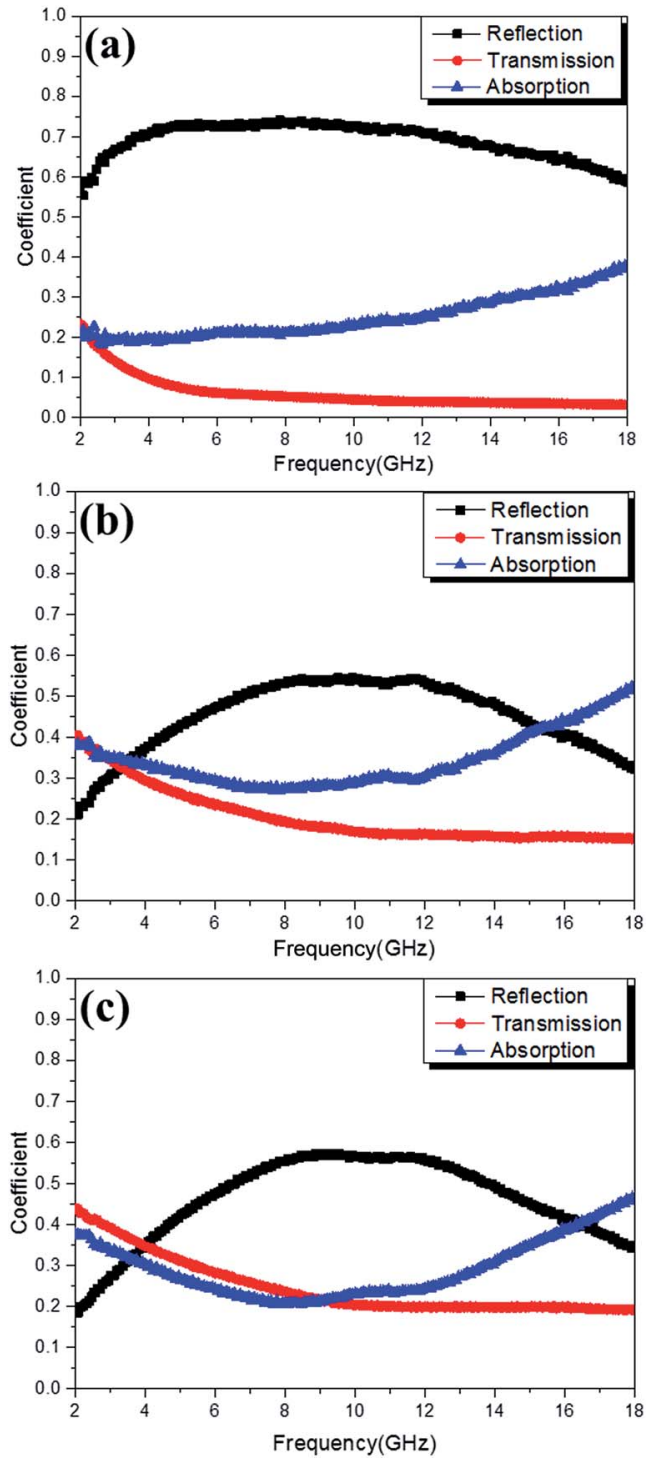

Fig. 12 The reflectance coefficient ( $R$, black curves), transmittance coefficient ( $T$, red curves) and absorption coefficient ( $A$, blue curves) of electromagnetic wave for DSCHP-S14 (a), DSCHP-S23 (b) and DSCHP-S33 (c)

the absorption coefficients of DSCHP-S33 become larger than the values of DSCHP-S23 due to the improving magnetic loss (Fig. S18b†) resulting from the eddy current loss (Fig. 9). However, the lower absorption coefficient and the larger transmittance coefficient of DSCHP-S33 than DSCHP-S23 result in an obviously different microwave reflection loss. As Fig. 11c shown, the max intensity of reflection loss of DSCHP-S33 decreased with the thickness increased. Based on the quarterwavelength cancellation model, much more electromagnetic microwave transmit the absorbers and reflect on the metal backplane out of phase by $180^{\circ}$, which could easily bring out the extinction at the absorber-free space interface with the thinner thickness, the increased thickness obstruct the transmission. At this time, the interference attenuation at the absorber-free space interface could apparently contribute to the significant development of reflection loss rather than absorption attenuation. Compared with Fig. 10, it is also proven that the excellent electromagnetic wave absorption are strongly dependent on the efficient complementarities between the relative permittivity and permeability than merely a high dielectric loss. ${ }^{5}$ On the other hand, the hollow core-shell structure of DSCHPs have an evident effect on reflection loss on account of geometrical absorption/scattering effect and interference attenuation. ${ }^{6,11,15,77,78}$ More and more electromagnetic microwave penetrates and is trapped in the hollow structure particles, electromagnetic energy is transformed to heat energy or other forms of energy, resulting in dissipating internally, ${ }^{12,79}$ as shown in Fig. S19b. $\dagger$

Above all, the excellent microwave absorption performance of DSCHPs depending on the heterogeneous phase assembly NiFeP shells could be explained by the following facts. Firstly, the Fe depositing in the Ni metal shell has a significant effect on the reduction of the dielectric constant and dielectric loss because of the lowering of the electrical conductivity ${ }^{53}$ showing improve dielectric relaxation process, which can be ascribed to more space charge polarization on the surfaces between metal shells and insulator $\mathrm{SiO}_{2}$ shells. At the same time, it induces the increase of the magnetic permeability and the magnetic loss due to the magnetic anisotropy. Thus, the DSCHPs have a better impedance match between the absorbers and free space, which results from the more nearly values of dielectric loss tangent and magnetic loss tangent, in other words, the permittivity is close to the permeability ${ }^{80}$ Because of the better impedance, it can makes more incident electromagnetic wave enter the absorbers to be attenuated. Secondly, the interference attenuation caused by incident microwave and reflection microwave also have a significant improvement of reflection loss. Thirdly, more and more electromagnetic microwave penetrate and is trapped in the hollow structure particles, electromagnetic energy is transformed to heat energy or other forms of energy, resulting in dissipating internally.

\section{Conclusions}

In summary, a novel cost effective strategy involving spray drying, simultaneously silicification and surface decoration with active sites, and finally directed growth of magnetic metal shells was found for the controlled preparation of double shell composite hollow particles (DSCHPs) with silica (inner shell) and magnetic metal (outer shell) shells in large scale. Activated silica hollow particles with high chemical durability and thermostability were obtained through spray drying pelleting with water glass as the starting material, and subsequent simultaneously silicification and activation in acid solution. Afterwards, light weight (1.1-2.35 $\left.\mathrm{g} \mathrm{cm}^{-3}\right)$ DSCHPs with metallic outer shell were fabricated through in situ chemical reduction of metal ions and directed assembly of the as-formed metallic nanocrystals. The thickness of the metallic shell can be tailored simply and reliably by varying the experimental conditions. The silica-NiFeP double shell hollow particles have excellent microwave absorption performances depending on the shell composition and thickness. DSCHPs with $\mathrm{Ni}-\mathrm{Fe}-\mathrm{P}$ alloy shell exhibited a maximum reflection loss of $45.92 \mathrm{~dB}$ at $15.92 \mathrm{GHz}$ and a broad effective absorption bandwidth of $4 \mathrm{GHz}$ with a thin absorbing layer thickness $1.5 \mathrm{~mm}$. 


\section{Acknowledgements}

This work was supported by the National Natural Science Foundation of China (projects No. 51102248) and the National key research and development program of China (projects No. 2016YFC0304505).

\section{Notes and references}

1 Y. Ren, C. Zhu, S. Zhang, C. Li, Y. Chen, P. Gao, P. Yang and Q. Ouyang, Nanoscale, 2013, 5, 12296.

2 Y. Du, W. Liu, R. Qiang, Y. Wang, X. Han, J. Ma and P. Xu, ACS Appl. Mater. Interfaces, 2014, 6, 12997.

3 Y. Li, J. Zhang, Z. Liu, M. Liu, H. Lin and R. Che, J. Mater. Chem. C, 2014, 2, 5216.

4 B. Wen, M. Cao, M. Lu, W. Cao, H. Shi, J. Liu, X. Wang, H. Jin, X. Fang and W. Wang, Adv. Mater., 2014, 26, 3484.

5 J. Jiang, D. Li, D. Geng, J. An, J. He, W. Liu and Z. Zhang, Nanoscale, 2014, 6, 3967.

6 J. Liu, R. Che, H. Chen, F. Zhang, F. Xia, Q. Wu and M. Wang, Small, 2012, 8, 1214.

7 C. Hu, Z. Mou, G. Lu, N. Chen, Z. Dong, M. Hu and L. Qu, Phys. Chem. Chem. Phys., 2013, 15, 13038.

8 M. S. Cao, J. Yang, W. L. Song, D. Q. Zhang, B. Wen, H. B. Jin, Z. L. Hou and J. Yuan, ACS Appl. Mater. Interfaces, 2012, 4, 6949.

9 G. Wang, Z. Gao, S. Tang, C. Chen, F. Duan, S. Zhao, S. Lin, Y. Feng, L. Zhou and Y. Qin, ACS Nano, 2012, 6, 11009.

10 J. Liu, J. Cheng, R. Che, J. Xu, M. Liu and Z. Liu, ACS Appl. Mater. Interfaces, 2013, 5, 2503.

11 J. Liu, J. Xu, R. Che, H. Chen, Z. Liu and F. Xia, J. Mater. Chem., 2012, 22, 9277.

12 R. Panigrahi and S. K. Srivastava, Sci. Rep., 2015, 5, 7638.

13 K. Yuan, R. Che, Q. Cao, Z. Sun, Q. Yue and Y. Deng, ACS Appl. Mater. Interfaces, 2015, 7, 5312.

14 R. Pang, X. Hu, S. Zhou, C. Sun, J. Yan, X. Sun, S. Xiao and P. Chen, Chem. Commun., 2014, 50, 12493.

15 J. Liu, J. Xu, R. Che, H. Chen, M. Liu and Z. Liu, Chem.-Eur. J., 2013, 19, 6746.

16 X. W. D. Lou, L. A. Archer and Z. Yang, Adv. Mater., 2008, 20, 3987.

17 Y. Zhao and L. Jiang, Adv. Mater., 2009, 21, 3621.

18 C. C. Yec and H. C. Zeng, J. Mater. Chem. A, 2014, 2, 4843.

19 H. J. Fan, U. Gösele and M. Zacharias, Small, 2007, 3, 1660.

20 G. Zhang and X. W. D. Lou, Angew. Chem., Int. Ed., 2014, 53, 9041.

21 J. Chen, D. Wang, J. Qi, G. Li, F. Zheng, S. Li, H. Zhao and Z. Tang, Small, 2014, 11, 420.

22 Z. An and J. Zhang, ACS Appl. Mater. Interfaces, 2013, 5, 989.

23 Z. Wu, W. D. Wu, W. Liu, C. Selomulya, X. D. Chen and

D. Zhao, Angew. Chem., Int. Ed., 2013, 52, 13764.

24 Z. An, J. Zhang and S. Pan, Dalton Trans., 2010, 39, 3378.

25 T. Liu, Y. Pang, M. Zhu and S. Kobayashi, Nanoscale, 2014, 6, 2447.

26 Q. Liu, Q. Cao, X. Zhao, H. Bi, C. Wang, D. S. Wu and R. Che, ACS Appl. Mater. Interfaces, 2015, 7, 4233.
27 X. C. Zhao, Z. M. Zhang, L. Y. Wang, K. Xi, Q. Q. Cao, D. H. Wang, Y. Yang and Y. W. Du, Sci. Rep., 2013, 3, 3421.

28 G. Tong, J. Yuan, W. Wu, Q. Hu, H. Qian, L. Li and J. Shen, CrystEngComm, 2012, 14, 2071.

29 B. U. Yoo, M. H. Han, H. H. Nersisyan, J. H. Yoon, K. J. Lee and J. H. Lee, Microporous Mesoporous Mater., 2014, 190, 139.

30 L. Sierra, B. Lopéz, H. Gil and J. L. Guth, Adv. Mater., 1999, 11, 307.

31 W. D. Bonivert, F. Altmayer, K. R. Newby, K. J. Gatchel, F. Clay, R. F. Lee, M. Faulman, E. W. Brooman and H. Tilton, Plat. Surf. Finish., 1995, 82, 29.

32 E. Asenath-Smith, R. Hovden, L. F. Kourkoutis and L. A. Estroff, J. Am. Chem. Soc., 2015, 137, 5184.

33 M. Luechinger, R. Prins and G. D. Pirngruber, Microporous Mesoporous Mater., 2005, 85, 111.

34 P. A. Heiney, K. Grüneberg, J. Fang, C. Dulcey and R. Shashidhar, Langmuir, 2000, 16, 2651.

35 Z. Luan, J. A. Fournier, J. B. Wooten and D. E. Miser, Microporous Mesoporous Mater., 2005, 83, 150.

36 C. Oh, J. H. Lee, Y. G. Lee, Y. H. Lee, J. W. Kim, H. H. Kang and S. G. Oh, Colloids Surf., B, 2006, 53, 225.

37 I. G. Casella and M. Contursi, J. Electroanal. Chem., 2006, 588, 147.

38 Y. Wang, J. Qu, R. Wu and P. Lei, Water Res., 2006, 40, 1224.

39 E. Merlen, P. Beccat, J. C. Bertolini, P. Delichère, N. Zanier and B. Didillon, J. Catal., 1996, 159, 178.

40 Z. Yang, Z. Li, L. Yu, Y. Yang and Z. Xu, J. Mater. Chem. C, 2014, 2, 7583.

41 D. Myers, Surfaces, Interfaces, and Colloids: Principles and Applications, Wiley, New York, 1999.

42 S. P. Pujari, L. Scheres, A. T. M. Marcelis and H. Zuilhof, Angew. Chem., Int. Ed., 2014, 53, 6322.

43 L. M. Ang, T. S. A. Hor, G. Q. Xu, C. H. Tung, S. Zhao and J. L. S. Wang, Chem. Mater., 1999, 11, 2115.

44 R. Iler, The chemistry of silica, Wiley, 1979.

45 I. P. Vyrodov, J. Phys. Chem., 1968, 42, 37.

46 L. G. Svendsen, T. Osaka and H. Sawai, J. Electrochem. Soc., 1983, 11, 130.

47 T. Osaka, H. Takematsu and K. Nihei, J. Electrochem. Soc., 1980, 127, 1021.

48 J. Shu, B. P. A. Grandjean, E. Ghali and S. Kaliaguine, J. Electrochem. Soc., 1993, 140, 3175.

49 J. Shu, B. P. A. Grandjean, A. Vanneste and S. Kaliaguine, Can. J. Chem. Eng., 1991, 69, 1036.

50 B. Zhao, G. Shao, B. Fan, W. Zhao and R. Zhang, Phys. Chem. Chem. Phys., 2015, 17, 2531.

51 L. Wang, Y. Huang, X. Ding, P. Liu and M. Zong, RSC Adv., 2013, 3, 23290.

52 P. C. Watts, W. K. Hsu, A. Barnes and B. Chambers, Adv. Mater., 2003, 15, 600.

53 S. T. Kim and S. S. Kim, J. Appl. Phys., 2014, 115, 17 A528.

54 S. S. Kim, S. T. Kim, Y. C. Yoon and K. S. Lee, J. Appl. Phys., 2005, 97, 10F905.

55 S. Ramo, R. W. John and V. D. Theodore, Fields and waves in communication electronics, John Wiley \& Sons, New York, 2008. 
56 Y. Duan, Z. Liu, H. Jing, Y. Zhang and S. Li, J. Mater. Chem., 2012, 22, 18291.

57 Y. J. Chen, F. Zhang, G. G. Zhao, X. Y. Fang, H. B. Jin, P. Gao, C. L. Zhu, M. S. Cao and G. Xiao, J. Phys. Chem. C, 2010, 114, 9239.

58 L. Kong, X. Yin, Y. Zhang, X. Yuan, Q. Li, F. Ye, L. Cheng and L. Zhang, J. Phys. Chem. C, 2013, 117, 19701.

59 H. Yu, T. Wang, B. Wen, M. Lu, Z. Xu, C. Zhu, Y. Chen, X. Xue, C. Sun and M. Cao, J. Mater. Chem., 2012, 22, 21679. 60 P. Liu, Y. Huang, J. Yan, Y. Yang and Y. Zhao, ACS Appl. Mater. Interfaces, 2016, 8, 5536.

61 M. Fu, Q. Jiao and Y. Zhao, J. Mater. Chem. A, 2013, 1, 5577. 62 D. Chung, Carbon, 2012, 50, 3342.

63 H. Wang, Y. Dai, W. Gong, D. Geng, S. Ma, D. Li, W. Liu and Z. Zhang, Appl. Phys. Lett., 2013, 102, 223113.

64 T. Sourmail, Prog. Mater. Sci., 2005, 50, 816.

65 A. Aharoni, J. Appl. Phys., 1991, 69, 7762.

66 X. Li, J. Feng, Y. Du, J. Bai, H. Fan, H. Zhang, Y. Peng and F. Li, J. Mater. Chem. A, 2015, 3, 5535.

67 T. Liu, X. Xie, Y. Pang and S. Kobayashi, J. Mater. Chem. C, 2016, 4, 1727.

68 X. D. Guo, X. J. Qiao, Q. G. Ren, X. Wan, W. C. Li and Z. G. Sun, Appl. Phys. A, 2015, 120, 43.
69 B. Qu, C. Zhu, C. Li, X. Zhang and Y. Chen, ACS Appl. Mater. Interfaces, 2016, 8, 3730.

70 S. Zhang, Q. Jiao, Y. Zhao, H. Li and Q. Wu, J. Mater. Chem. A, 2014, 2, 18033.

71 R. Che, L. M. Peng, X. F. Duan, Q. Chen and X. Liang, Adv. Mater., 2004, 16, 401.

72 H. Lv, X. Liang, G. Ji, H. Zhang and Y. Du, ACS Appl. Mater. Interfaces, 2015, 7, 9776.

73 P. Miles, W. Westphal and A. Von Hippel, Rev. Mod. Phys., 1957, 29, 279.

74 N. Li, Y. Huang, F. Du, X. He, X. Lin, H. Gao, Y. Ma, F. Li, Y. Chen and P. C. Eklund, Nano Lett., 2006, 6, 1141.

75 J. Wang, C. Xiang, Q. Liu, Y. Pan and J. Guo, Adv. Funct. Mater., 2008, 18, 2995.

76 W. Li, B. Lv, L. Wang, G. Li and Y. Xu, RSC Adv., 2014, 4, 55738.

77 J. Liu, J. Cheng, R. Che, J. Xu, M. Liu and Z. Liu, J. Phys. Chem. C, 2012, 117, 489.

78 J. Xu, J. Liu, R. Che, C. Liang, M. Cao, Y. Li and Z. Liu, Nanoscale, 2014, 6, 5782.

79 Q. Liu, Q. Cao, H. Bi, C. Liang, K. Yuan, W. She, Y. Yang and R. Che, Adv. Mater., 2016, 28, 486.

80 D. Micheli, C. Apollo, R. Pastore and M. Marchetti, Compos. Sci. Technol., 2010, 70, 400. 